\title{
Reviewer Acknowledgements for Global Journal of Health Science, Vol. 13, No. 1
}

Global Journal of Health Science wishes to acknowledge the following individuals for their assistance with peer review of manuscripts for this issue. Their help and contributions in maintaining the quality of the journal are greatly appreciated.

Global Journal of Health Science is recruiting reviewers for the journal. If you are interested in becoming a reviewer, we welcome you to join us. Please contact us for the application form at: gjhs@ccsenet.org.

\section{Reviewers for Volume 13, Number 1}

Althea Jane Gamble Blakey, University of Otago, New Zealand

Ahmed Hassan Ghada, Menoufia University, Egypt

Ama Pokuaa Fenny, University of Ghana, Ghana

Angel Alfonso Velarde Lopez, University of Pennsylvania, Guatemala

Darampal Dambhare, Mahatma Gandhi Institute of Medical Sciences, India

Evangelia Mavrikaki, National \& Kapodistrian University of Athens, Greece

Francisco Rodenas Rigla, University of Valencia, Spain

Gabriel Gulis, University of Southern Denmark, Denmark

Hilal Hamood Alrahbi, Diwan of Royal Court-Oman, Oman

Horng-Jyh Tsai, Kuang Tien General Hospital, Taiwan

Meng Zhao, Texas A\&M University at Corpus Christi, United States of America

Mini Sood, Monash University Malaysia, Malaysia

Raymond Jagessar, University of Guyana, Guyana

Sara Melo, Queen's University Belfast, United Kingdom

Valery Piacherski, Mogilev Regional Hospital, Belarus 